www.jmscr.igmpublication.org

Impact Factor 5.244

Index Copernicus Value: 5.88

ISSN (e)-2347-176x ISSN (p) 2455-0450

crossref DOI:_http://dx.doi.org/10.18535/jmscr/v4i3.26

Journal Of Medical Science And Clinical Research

IGM Publication

An Official Publication of IGM Publication

\title{
Congenital Cystic Adenomatoid Malformation: Case Report
}

\author{
Mohammed Junaid Ansari ${ }^{1}$, ${ }^{*}$ Shahla Abrar ${ }^{1}$, Tanvir Roshan Khan ${ }^{2}$ \\ ${ }^{1}$ Department of Pediatrics, B.R.D. Medical College, Gorakhpur, UP, INDIA \\ ${ }^{2}$ Department of Pediatric Surgery, KGMU, Lucknow, UP, INDIA
}

\begin{abstract}
Congenital Cystic Adenomatoid Malformation (CCAM) is a rare development abnormality of the lung occurring in 1-4 / 100,000 live birth.it is often confused with pneumatocoele or pneumothorax which are common in developing countries. We report here a case of 5 months old baby with features of respiratory distress since birth and CECT thorax suggestive of large cystic lesion of left lung i.e., CCAM.

Keywords - CCAM, rare, Cystic lesion, Respiratory distress.
\end{abstract}

\section{INTRODUCTION}

Cystic lucent lung lesion on chest radiograph is a common finding in children presenting with acute respiratory distress. The prominent differentials for cystic lucent chest lesion on chest radiograph in infants and young children (under 3 years of age) with respiratory distress are post-infective pneumatocele, pneumothorax, congenital diaphragmatic hernia (CDH), congenital cystic adenomatoid malformation (CCAM), congenital lobar emphysema (CLE), pulmonary sequestration, bronchogenic cyst, and bullous lung disease ${ }^{[1,2,3]}$. Congenital cystic lung lesions are relatively rare in incidence and have a varied clinical presentation. ${ }^{[4]}$ Majority of the patients usually present in infancy or within the first 3 years of life. On chest radiograph, these patients usually present as cystic lucent lung lesions with or without mass effect. In developing countries, the incidence of chest infection and infectionrelated complications (pneumothorax and pneumatoceles) is high, and they are considered to be the more common causes of lucent cystic lesions on chest radiograph in patients with respiratory distress. [5]. Congenital cystadenomatoid malformation (CCAM), a rare type of developmental anomaly of the lung was first acknowledged as a separate entity and introduced into English literature by Chin and Tang in 1949. ${ }^{[6]}$ The major errors in diagnosis are due to the inability to differentiate CCAM from tension pneumothorax/pneumatocele. We report a case of infant who was first misinterpreted as pneumothorax and treated accordingly and then later when not improved with antibiotics and intercostal drainage, it was diagnosed as a case of CCAM after CECT thorax was done.

\section{CASE REPORT}

A 5 month old infant weighing $5.2 \mathrm{~kg}$, presented with chief complaints of cough and fast breathing since birth which was gradual in onset and more during feeding and non-progressive in nature. There was also a history of fever since 5 days. 


\section{JMSCR Vol||04||Issue||03||Page 9729-9732||March}

There was no history of cyanosis, vomiting, decreased feeding, loose motions, abnormal body movements, fever or bleeding from any site. There was no history of perinatal hypoxic insult, prolonged labour, meconium aspiration. Baby was admitted at 5 days of age for neonatal hyperbilrubinemia, and received phototherapy. Antenatal history of the mother was uneventful. On examination, baby had respiratory distress (Respiratory rate $>70$ /minute) and air entry was significantly decreased on left side of chest. Percussion note was hyper resonant. X-ray chest was done, and was suggestive of pneumothorax on left side with mediastinal shift to right side (figure 1). So a preliminary impression of Staphylococcal pneumonia was made and patient was treated with IV Cloxacillin and intercostal drainaige was done. After one week of treatment patient did not show any significant improvement in respiratory distress or air entry. Repeated chest Xray was also similar to the previous $\mathrm{X}$ ray with mediastinal shift. So computerised tomography (CT) chest was done to rule out any cystic disease of the lung. It was suggestive of cystic lesion in left upper and middle lobe and was described by radiologist as congenital adenomatoid malformation (figure 2). ICD (intercostal drainaige ) tube was then removed and patient was then referred to Pediatric surgery.

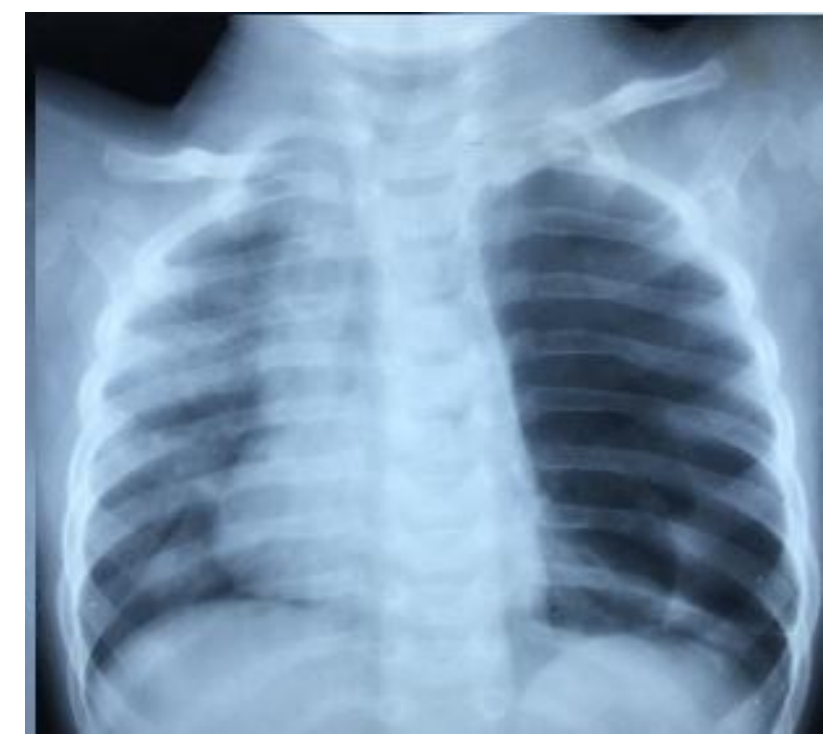

Figure 1- Chest $X$ ray showing cystic lesions left lung with mediastinal shift
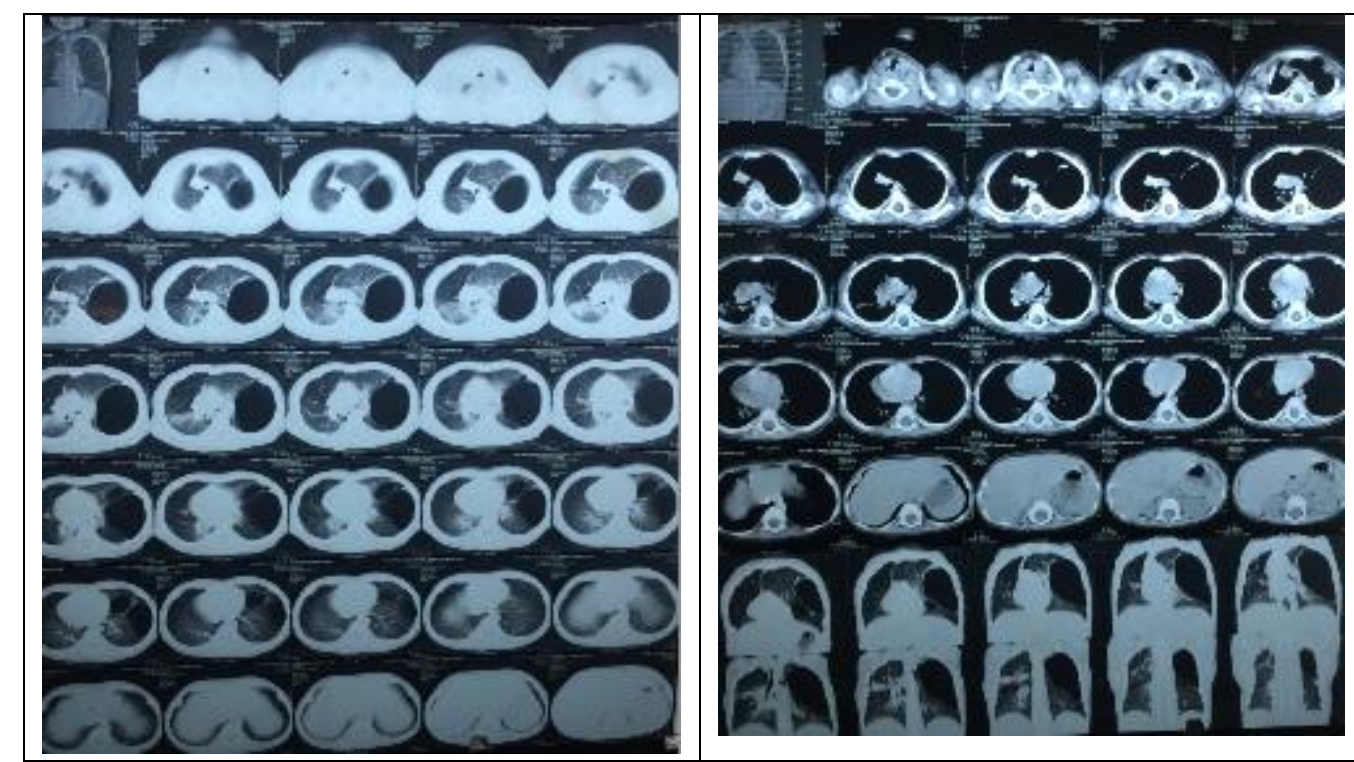

Figure 2- A large loculated thin walled air filled cavity is seen in left upper and middle lung field causing mass effect over the underlying lung parenchyma and mediastinal with shift to right side. Oligemic lung field is also seen in the right upper and middle zone predominantly and anterior aspect. Ground glass changes in the rest of the lung parenchyma predominantly in the perihilar area with parenchymal exudates along the oblique fissures, lower part on the right side - CCAM. 


\section{DISCUSSION}

Congenital cystic adenomatoid malformation is an uncommon congenital malformation of the lung that arises from excessive disorganised proliferation of tubular bronchial structures excluding the alveoli. The left lung is involved as often as the right lung with single lobe disease observed four times more often than multilobe disease. Cases are typically indentified prenatally by routine ultrasonography screening. ${ }^{[7]}$ Most postnatally identified cases present in the newborn period. The most common mode of presentation is acute respiratory distress secondary to the cyst expanding and compressing its surrounding structures. The distress occurs through a ballvalve mechanism leading to air trapping. This mode of presentation is common during the neonatal period. Child may also present with recurrent infection, hemoptysis, dyspnea, chest pain, cough, fever, failure to thrive and on examination tachypnea, pneumothorax, cyanosis, accessory muscle use, grunting may be present. It may remain asymptomatic and be discovered later in life on routine chest films or present after the neonatal period as recurrent pneumonia. ${ }^{[8]} \mathrm{CCAM}$ may present in the older child and adults as an incidental finding or secondary to repeated infection. ${ }^{[9,10]}$ In adult patient, CCAM is a nidus for pneumonia, abscess formation, fungal infections, spontaneous pneumothorax, hemoptysis, air embolism, intralobar sequestration, and development of bronchogenic carcinoma. [11,12,13]

Chest X-ray, computed tomography (CT), and magnetic resonance imaging (MRI) are helpful in diagnosis. ${ }^{[14]}$ Stocker et al. classified CCAM into three types depending upon the size of cysts contained in the lesion. ${ }^{[15]}$ The appearance of the lesion on chest radiograph and CT depends upon the number, size, and amount of fluid within the lesion. On plain radiograph, CCAM can present as a cystic lucent lung lesion with or without mass effect. There are multiple isolated reports of chest tube insertion in CCAM, after mistaking it for complicated pneumatocele and tension pneumothorax. ${ }^{[16,17]}$
Serial antenatal sonographic evaluation, good obstetric care, and delivery at a tertiary care center are preferred plan of treatment for antenataly detected cases. Postnatal and in adults patients, lobectomy is the treatment of choice for symptomatic cases. ${ }^{[14,18-20]}$

However, there is a controversy whether or not all cases be subjected to surgery. Surgery is indicated for the following reasons: $(i)$ definite histological diagnosis, (ii) history of recurrent infections, and (iii) risk of malignancies which have been rarely reported. [21] As we could not make the histological diagnosis of our patient and there was no history suggestive of infection in the past surgery can be withheld. Although, the outcome of lobectomy/pneumonectomy is good in children. In lobectomy the remaining lung grows and expands well enough so that total lung volume and pulmonary function tests return to normal. ${ }^{\text {[2] }}$ This response is most vigorous in the very young because new acini and alveoli form upto 5 years age ${ }^{[23]}$. Post-resection majority of patients have an excellent result. Younger groups have lower ratio of residual volume to total lung capacity and higher maximum breathing capacity. This suggests that hyperplasia rather than over distension occurs in the remaining lung. ${ }^{[23]}$

\section{REFERENCES}

1. Godwin JD, Webb WR, Savoca CJ, Gamsu G, Goodman PC. Multiple, thinwalled cystic lesions of the lung. AJR Am J Roentgenol. 1980;135:593-604.

2. Dillman JR, Sanchez R, Ladino-Torres MF, Yarram SG, Strouse PJ, Lucaya J. Expanding upon the unilateral hyperlucent hemithorax in children radiographics, 2011 31:723-41.

3. Visrutaratna P, Euathrongchit J, Kattipattanapong V. Clinics in diagnostic imaging (86). Ruptured bronchogenic cyst. Singapore Med J. 2003;44:325-9.

4. Schwartz MZ, Ramachandran P. Congenital malformations of the lung and mediastinum-a quarter century of 
experience from a single institution. J Pediatr Surg. 1997;32:44-7.

5. Kunyoshi V, Cataneo D, Cataneo A. Complicated pneumonias with empyema and/or pneumatocele in children. Pediatr Surg Int. 2006;22:186-90.

6. Chi'n KY, Tang MY. Congenital cystic adenomatoid malformation of one lobe of a lung with general anasarca. Arch Pathol 1949; 48: 221-229.

7. Laberge JM, Flageole H, Pugash D, Khalife S, Blair G, Filiatrault D, et al. Outcome of the prenatally diagnosed CCAM: a Canadian experience. Fetal Diagn Ther 2001;16(3):178-86.

8. Sindhwani G, Whig J, Gupta A, Rawat J. Tuberculosis in congeniatal adenomatoid malformation: a rare presentation. Lung India 2007;24(4):148-9.

9. Luján M, Bosque M, Mirapeix RM, Marco MT, Asensio O, Domingo C. Late onset congenital cystic adenomatoid malformation of the lung. Embryology, clinical symptomatology, diagnostic procedures, therapeutic approach and clinical followup. Respiration2002;69(2):148-54.

10. Parikh D, Samuel M. Congenital cystic lung lesions: is surgical resection essential? Padiatr Pulmonol 2005; 40(6): 533-7.

11. Cass DL, Olutoye OO, Cassady CI, Moise KJ, Johnson A, Papanna R, et al. Prenatal diagnosis and outcome of fetal lung masses. J Pediatr Surg. 2011;46:292-8.

12. Zeidan S, Hery G, Lacroix F, Gorincour G, Potier A, Dubus JC, et al. Intralobar sequestration associated with cystic adenomatoid malformation: Diagnostic and thoracoscopic pitfalls. Surg Endosc. 2009;23:1750-3.

13. Belcher E, Lawson MH, Nicholson AG, Davison A, Goldstraw P. Congenital cystic adenomatoid malformation presenting as in-flight systemic air embolisation. Eur Respir J. 2007;30:801-4.
14. Sahu S, Muthuvel S, Naware SS, Dhavala SS. Congenital cystic adenomatoid malformation of lung. Med $\mathrm{J}$ Armed Forces India. 2008;64:268-9.

15. Stocker JT, Madewell JE, Drake RM. Congenital cystic adenomatoid malformation of the lung. Classification and morphologic spectrum. Hum Pathol 1977;8:155-71.

16. Nandi M, Mondal R. Congenital cystic disorders of lung masquerading as complicated pneumonia and pneumothorax: A case series. Eastern J Med 2010;15:125-7.

17. Kumar B, Agrawal LD, Sharma SB. Congenital bronchopulmonary malformations: A single-center experience and a review of literature. Ann Thorac Med 2008;3:135-9.

18. Feng A, Cai H, Sun Q, Zhang Y, Chen L, Meng F. Congenital cystic adenomatoid malformation of lung in adults: 2 rare cases report and review of the literature. Diagn Pathol. 2012;7:37.

19. Belcher E, Lawson MH, Nicholson AG, Davison A, Goldstraw P. Congenital cystic adenomatoid malformation presenting as in-flight systemic air embolisation. Eur Respir J. 2007;30:801-4.

20. Loachimescu OC, Mehta AC. From cystic pulmonary airway malformation, to bronchioloalveolar carcinoma and adenocarcinoma of the lung. Eur Respir J. 2005;26:1181-7.

21. Weinblatt ME, Siegel SE, Isaacs $H$. Pulmonary blastoma associated with cystic lung disease. Cancer 1982; 49: 669-671.

22. Filler J. Effects upon pulmonary function of lobectomy performed during childhood. Am Rev Respir Dis 1964; 89: 801-810.

23. Peters RM, Wilcox BR, Schultz EH. Pulmonary resection in children: Longterm effect on function and lung growth. Ann Surg 1964; 159: 652-660. 